\title{
Antifungigrama para comprovar o potencial de ação dos extratos vegetais hidroglicólicos sobre Candida sp. (Berkhout)
}

\author{
GLEHN, E.A.V.; RODRIGUES, G.P.S.* \\ IMES FAFICA Rodovia Washington Luis, SP 310, Km 382 CEP: 15800-000, Catanduva-Brasil *gi.psr@uol.com.br
}

\begin{abstract}
RESUMO: A candidíase vaginal é uma doença causada, na maioria das vezes, pelo fungo do gênero Candida sp, que habita o trato gastrintestinal e geniturinário da espécie humana e pode tornar-se patogênico sob determinadas condições. A maioria dos indivíduos desenvolve defesas imunológicas que impedem a proliferação e desenvolvimento de candidíase localizada ou disseminada. Embora a causa exata do aumento de espécies não-albicans seja desconhecida, há evidências de que a própria terapia antifúngica possa estar contribuindo para o processo. Linhagens de C. glabrata são mais resistentes aos imidazólicos do que a C. albicans, sendo necessária uma concentração 10 vezes superior de miconazol para eliminar a C. glabrata quando comparada a $C$. albicans. Foi realizado um antifungigrama testando o potencial de ação de produtos vegetais sobre o fungo Candida sp. Foi observado que, ocorreu inibição do fungo no contato com os extratos hidroglicólicos das plantas Arctium lappa L., Calendula officinalis L., Stryphnodendron adstringens (Mart.) Coville e Tabebuia avellanedae Lorentz ex Griseb. A importância deste trabalho reside na possibilidade de desenvolvimento de tratamento complementar, menos agressivo, de menor custo e sem toxidade, o que possibilitaria melhor qualidade de vida para portadoras de candidíase vaginal recorrente ou não.
\end{abstract}

Palavras-chave: candidíase, Arctium lappa, Calendula officinalis, Stryphnodendron adstringens, Tabebuia avellanedae

\begin{abstract}
Etest to confirm the action potential of plant hydroglycol extracts on Candida sp. (Berkhout). Vaginal candidiasis is a disease caused, in most cases, by the fungus of the genus Candida sp., which inhabits the gastrointestinal and genitourinary tracts of the human species and can become pathogenic under certain conditions. Most individuals develop immune defenses that prevent the proliferation and the development of localized or disseminated candidiasis. Although the exact cause of the increase in non-albicans species is unknown, there is evidence that antifungal therapy itself may have contributed to it. Strains of $C$. glabrata are more resistant to imidazole than $C$. albicans, and a 10 -fold higher concentration of miconazole is required to eliminate $C$. glabrata compared to $C$. albicans. Etest was performed by testing the action potential of plant products on the fungus Candida sp. Inhibition of the fungus occurred when it was in contact with the hydroglycol extracts of plants Arctium lappa L., Calendula officinalis L., Stryphnodendron adstringens (Mart.) Coville and Tabebuia avellanedae Lorentz ex Griseb. The importance of this study lies in the possibility of developing a complementary treatment, less aggressive, of lower cost and without toxicity, which would allow better life quality for women with vaginal candidiases that are recurrent or not.
\end{abstract}

Key words: candidiasis, Arctium lappa, Calendula officinalis, Stryphnodendron adstringens, Tabebuia avellanedae

\section{INTRODUÇÃO}

A candidíase vaginal é doença causada pelo fungo do gênero Candida sp. que habita o trato gastrointestinal e geniturinário da espécie humana. Estes organismos são habitantes comensais, mas podem tornar-se patogênicos sob determinadas condições que alteram o ambiente vaginal (Carvalho, 2003).
De acordo com Holanda et al. (2007), o uso de roupas íntimas sintéticas e justas, leva a ocorrência de prurido, mucorréia, hiperemia, que, associado com a positividade de colonização de Candida albicans anal, aumenta em 3,7 vezes o resultado para candidíase vaginal sugerindo possível contaminação

Recebido para publicação em 03/06/2009

Aceito para publicação em 26/03/2012

Rev. Bras. PI. Med., Botucatu, v.14, n.3, p.435-438, 2012. 
a partir do ânus. A realização de estudos mais aprofundados que abordem fatores de risco pode identificar formas de prevenção a partir de mudanças de comportamento e hábitos.

A maior parte da literatura específica atual demonstra que entre 80 e $90 \%$ da microbiota fúngica é constituída por Candida albicans, o restante é atribuído a outras espécies, sendo as mais comuns C. glabrata ( 9 a $15 \%$ dos casos) e a C. tropicalis (até $15 \%$ dos casos) (Piato,1997; Freitas et al., 2003).

O diagnóstico da candidíase vaginal é de extrema importância, devendo-se evitar o tratamento excessivo e equivocado dessa vulvovaginite. A maioria das mulheres e dos próprios ginecologistas assume, como diagnóstico presuntivo, que todo e qualquer prurido genital acompanhado de corrimento vaginal seja causado por candidíase (Simões, 2005). O exame de cultura pode ser realizado especialmente nos casos de recidiva ou resistência aos tratamentos usuais (Freitas et al., 2003).

Estudos têm demonstrado que o tratamento oral com fármacos como fluconazol, cetoconazol e itraconazol são eficazes no tratamento da candidíase; no entanto, apresentam toxidade sistêmica que deve ser controlada, especialmente com o uso de cetoconazol. Esses agentes podem estar associados com elevação das enzimas hepáticas (Piato, 1997; Freitas et al., 2003).

Existem tratados que demonstram a utilização de plantas medicinais que datam de 1700 a.C. para aplicação na saúde humana. Civilizações tais como a egípcia, chinesa, grega e romana têm descrições de tratados de espécies vegetais e dos usos (Alonso, 2008). Na medicina popular as plantas medicinais podem ser utilizadas de várias formas, através de infusos, xaropes, unguentos e óleos voláteis.

A importância deste trabalho está no fato de pesquisar o potencial antifúngico dos extratos hidroglicólicos das plantas medicinais Arctium lappa L., Calendula officinalis L., Stryphnodendron adstringens (Mart.) Coville e Tabebuia avellanedae Lorentz ex Griseb, através do antifungigrama para possível tratamento da candidíase vaginal.

T. avellanedae L.G., Bignoniaceae, ipê roxo, é nativa das Américas e encontrada em todo o Brasil. Utiliza-se a entrecasca, na qual se encontram saponinas, resinas e lapachol. Tem ação antimicrobiana, antiinflamatória, analgésica, antineoplásica e antifúngica. O Dr. Walter Radamés Accorci, professor de Botânica da Esalq-USP, Piracicaba, em 1960, testou e comprovou propriedades imunoestimulantes da Tabebuia sp. (Silva, 2006). A literatura etnobotânica cita o uso das cascas da planta na medicina popular, sob forma de chá, como antiinfeccioso e antifúngico. Resultados de análise fitoquímica registram principalmente os componentes lapachol e lapachona, sendo que essas substâncias têm baixa toxidade (Teske \& Trentini, 2001; Lorenzi \& Matos, 2002).

A. lappa L., Compositae (Asteraceae), bardana, é planta estrangeira já adaptada ao Brasil. As partes utilizadas são as folhas frescas, raízes e sementes. Os princípios ativos correspondem às mucilagens, ao óleo essencial, aos taninos e glicosídeos. É usada desde a antiguidade tendo ação fungicida eficiente para tratamento de infecções no trato genital, permitindo a cicatrização de feridas e ulcerações. As folhas esmagadas e aplicadas em cataplasma sobre a pele têm ação bactericida e antimicótica sendo eficaz contra doenças de pele, como dermatoses úmidas e purulentas, acnes, eczemas, pruridos, tinha, seborreia da face ou do couro cabeludo e herpes simples. São empregadas internamente em decocção e infusão das folhas e raízes, bem como, a simples ingestão das sementes e raízes contra afecções de pele em geral, das vias urinárias, em casos de reumatismo e gota, de diabetes, em afecções gástricas e hepáticas (Teske \& Trentini, 2001; Lorenzi \& Matos, 2002).

C. officinalis L., Compositae (Asteraceae), calêndula, nativa das Ilhas Canárias e região Mediterrânea, é bem aclimatada no Brasil. As partes utilizadas são as folhas e inflorescências. Os princípios ativos são óleo essencial, flavonóides, mucilagens, saponinas, resinas e princípio amargo; foi bastante utilizada na guerra para tratamento tópico dos ferimentos e é considerada antiespasmódica, antiinflamatória, antisséptica, cicatrizante, depurativa, emenagoga, emoliente e sudorífica. O emprego é, principalmente, em feridas, úlceras, acnes, inflamações purulentas, pruridos e micoses de pele. A C. officinalis combate as infecções, tem ação antiinflamatória da pele e da mucosa, sendo muito usada em queimaduras suaves e tratamento de feridas de difícil cicatrização por ser estimulante da fagocitose e granulocitose (Teske \& Trentini, 2001; Lorenzi \& Matos, 2002).

S. adstringens (Mart.) Coville, Leguminosae (Mimosoideae), barbatimão, é planta típica do cerrado brasileiro. A parte utilizada é a entrecasca, destacando como princípios ativos os taninos, as mucilagens e os flavonóides. É cicatrizante, antisséptica, e antimicótica, sendo muito utilizada na medicina caseira. Entretanto, não deve ser usada com plantas ricas em alcalóides, por serem incompatíveis. O chá da entrecasca em uso externo é indicado para hemorragias uterinas, corrimentos vaginais, feridas ulcerosas e pele excessivamente oleosa. No caso de administração oral deve ser feito extrato hidroglicólico, o qual é preparado com duas colheres de sopa de casca picada em uma xícara de chá de álcool de cereais a $50 \%$, deixa-se em maceração por três dias, tomando-se uma colher de café do filtrado diluído em um pouco de água, três vezes ao

Rev. Bras. PI. Med., Botucatu, v.14, n.3, p.435-438, 2012. 
dia. Este preparado é indicado para inflamações da garganta, diarréias, corrimento vaginal e hemorragias. As pomadas e os cremes com 2 a $5 \%$ do extrato glicólico, podem ser usadas para uso externo. As sementes são altamente tóxicas (Lorenzi \& Matos, 2002).

\section{MATERIAL E MÉTODO}

\section{Extratos vegetais hidroglicólicos}

Para a elaboração dos extratos hidroglicólicos, a Professora Giselda P.S. Rodrigues, especialista em fitoterapia, fez a seleção das folhas das plantas de A. lappa, das flores de $C$. officinalis e da entrecasca de $S$. adstringens e de T. avellanedae. As espécies foram adquiridas no Herbário da Associação Beneficente Amigo Germano (Rua Vereador Guido Broglia no 1183, Vila Soto) e preparadas no laboratório do IMES-FAFICA.

Estudou-se a ação antifúngica dos extratos vegetais, os quais foram preparados na razão de uma parte da droga vegetal para cinco partes do líquido extrator, conforme a formulação de 100 gramas de planta seca, 1,5 gramas de nipagin, $250 \mathrm{~mL}$ de água destilada e $250 \mathrm{~mL}$ de propilenoglicol, os quais foram macerados por 15 dias, agitando-se por um minuto por dia, e seguindo para filtragem e armazenamento em local escuro à temperatura ambiente, de acordo com o método de Alonso (2008).

\section{Microrganismo}

O fungo Candida sp. foi fornecido pelo laboratório do Hospital Santa Casa de Votuporanga, onde foi realizada coleta de secreção vaginal de paciente que preenchia os critérios de secreção esbranquiçada e pastosa, prurido intenso, ardor ao urinar e edema de vulva. A secreção foi semeada em 2 placas de Petri (90 x $15 \mathrm{~mm}$ ) (placas mãe), sendo o meio para crescimento o Agar Sabourand Dextrosado e incubadas por 48 horas a $37^{\circ} \mathrm{C}$, em estufa de cultura 502 (FANEM-ORION). Após o crescimento, as placas foram mantidas em refrigerador a $4^{\circ} \mathrm{C}$ para interromper o processo de crescimento. Estes procedimentos foram efetuados no laboratório do IMES-FAFICA, de acordo com a metodologia descrita por Pelczar et al. (1996).

\section{Atividade antifúngica dos extratos vegetais}

Os estudos de atividade antifúngica dos extratos vegetais foram realizados através de 20 placas de Petri $(90 \times 15 \mathrm{~mm})$ contendo $20 \mathrm{~mL}$ de Agar Sabouraud solidificado, no qual foi depositado 1 $\mathrm{mL}$ de água destilada contaminada pela Candida sp. retirada das placas mãe através de alça de platina e espalhada com alça de vidro. Preparou-se 5 placas para cada extrato vegetal. Foram colocados 4 discos de papel filtro ( $6 \mathrm{~mm}$ de diâmetro), os quais ficaram em contato com os extratos vegetais, na concentração de $20 \%$. As placas foram encubadas em estufa a $37^{\circ} \mathrm{C}$ por 48 horas, tempo necessário para observar variações de resistência ou não do fungo Candida sp., de acordo com a metodologia descrita por Pelczar et al. (1996).

\section{RESULTADO E DISCUSSÃO}

Os resultados obtidos dos experimentos representados nas Tabelas 1, 2, 3 e 4 mostram que o fungo Candida sp. sofre ação fungistática principalmente dos extratos hidroglicólicos de $A$. lappa, C. officinalis e T. avellanedae, observados por meio da formação de halos e dos dados estatísticos nos quais as médias dos diâmetros dos halos foram referência para os demais parâmetros. Observou-se que o extrato hidroglicólico de $A$. lappa mostrou maior média de diâmetro de halo, o que significa maior área de ação sobre o fungo Candida sp., mesmo apresentando heterogeneidade nos valores de

TABELA 1. Medidas dos halos ( $\mathrm{mm}$ ) de A. lappa e dados estatísticos.

\begin{tabular}{lccccc}
\hline $\begin{array}{l}\text { Arctium } \\
\text { lappa }\end{array}$ & $\begin{array}{c}\text { Placa } \\
\mathbf{1}\end{array}$ & $\begin{array}{c}\text { Placa } \\
\mathbf{2}\end{array}$ & $\begin{array}{c}\text { Placa } \\
\mathbf{3}\end{array}$ & $\begin{array}{c}\text { Placa } \\
\mathbf{4}\end{array}$ & $\begin{array}{c}\text { Placa } \\
\mathbf{5}\end{array}$ \\
\hline Disco 1 & 4 & 0 & 3 & 5 & 4 \\
Disco 2 & 7 & 3 & 4 & 5 & 3 \\
Disco 3 & 6 & 2 & 4 & 6 & 3 \\
Disco 4 & 4 & 4 & 2 & 3 & 1 \\
Amplitude & 3 & 4 & 2 & 3 & 3 \\
Média & 5,2 & 2,2 & 3,2 & 4,7 & 2,7 \\
Variância & 2,2 & 2,9 & 0,91 & 1,6 & 1,6 \\
Desvio Padrão & 1,3 & 1,5 & 0,82 & 1,1 & 1,1 \\
\hline
\end{tabular}

TABELA 2. Medidas dos halos ( $\mathrm{mm}$ ) de C. officinalis e dados estatísticos.

\begin{tabular}{llllll}
\hline $\begin{array}{l}\text { Calendula } \\
\text { officinalis }\end{array}$ & $\begin{array}{c}\text { Placa } \\
\mathbf{1}\end{array}$ & $\begin{array}{c}\text { Placa } \\
\mathbf{2}\end{array}$ & $\begin{array}{c}\text { Placa } \\
\mathbf{3}\end{array}$ & $\begin{array}{c}\text { Placa } \\
\mathbf{4}\end{array}$ & $\begin{array}{c}\text { Placa } \\
\mathbf{5}\end{array}$ \\
\hline Disco 1 & 4 & 4 & 4 & 4 & 4 \\
Disco 2 & 3 & 3 & 2 & 3 & 1 \\
Disco 3 & 4 & 4 & 1 & 6 & 4 \\
Disco 4 & 4 & 3 & 3 & 2 & 3 \\
Amplitude & 3 & 4 & 2 & 3 & 3 \\
Média & 3,7 & 3,5 & 2,5 & 3,7 & 3 \\
Variância & 0,25 & 0,33 & 1,7 & 2,9 & 2 \\
Desvio Padrão & 0,5 & 0,5 & 1,3 & 1,7 & 1,4 \\
\hline
\end{tabular}


TABELA 3. Medidas dos halos $(\mathrm{mm})$ de $S$. adstringens e dados estatísticos.

\begin{tabular}{llllll}
\hline Stryphpdendron & Placa & Placa & Placa & \multicolumn{2}{c}{ Placa Placa } \\
adstringens & $\mathbf{1}$ & $\mathbf{2}$ & $\mathbf{3}$ & $\mathbf{4}$ & $\mathbf{5}$ \\
\hline Disco 1 & 1 & 2 & 1 & 1 & 2 \\
Disco 2 & 1 & 0 & 0 & 0 & 0 \\
Disco 3 & 0 & 0 & 0 & 0 & 0 \\
Disco 4 & 0 & 0 & 0 & 0 & 0 \\
Amplitude & 1 & 2 & 1 & 1 & 2 \\
Média & 0,50 & 0,50 & 0,25 & 0,25 & 0,50 \\
Variância & 0,33 & 1,00 & 0,25 & 0,25 & 1,00 \\
Desvio Padrão & 0,50 & 0,86 & 0,43 & 0,43 & 0,86 \\
\hline
\end{tabular}

TABELA 4. Medida dos halos ( $\mathrm{mm}$ ) de T.avellanedae e dados estatísticos.

\begin{tabular}{lllllll}
\hline Tabebuia & \multicolumn{2}{c}{ Placa } & Placa & \multicolumn{2}{c}{ Placa } & \multicolumn{2}{c}{ Placa Placa } \\
adstringens & $\mathbf{1}$ & $\mathbf{2}$ & $\mathbf{3}$ & $\mathbf{4}$ & $\mathbf{5}$ \\
\hline Disco 1 & 3 & 4 & 3 & 5 & 4 \\
Disco 2 & 5 & 8 & 4 & 3 & 2 \\
Disco 3 & 3 & 5 & 4 & 4 & 3 \\
Disco 4 & 3 & 5 & 3 & 5 & 4 \\
Amplitude & 2 & 3 & 1 & 2 & 2 \\
Média & 3,5 & 5,5 & 3,5 & 4,2 & 3,2 \\
Variância & 1,00 & 3,00 & 0,33 & 0,91 & 0,91 \\
Desvio Padrão & 1,00 & 1,70 & 0,57 & 0,95 & 0,95 \\
\hline
\end{tabular}

variância e desvio padrão.

De acordo com a Tabela 3, observa-se que pelas medidas de diâmetro dos halos do extrato hidroglicólico de $S$. adstringens a inibição do fungo foi menor embora experimentalmente com halos bem definidos.

A comparação de dados foi feita com placa controle, na qual houve crescimento por toda a extensão.

As atividades antifúngicas dos extratos hidroglicólicos A. lappa, C. officinalis, S. adstringens e T.avellanedae, possivelmente, estão associadas à presença de princípios ativos, tais como os taninos, que lesionam as moléculas da parede celular de fungos e bactérias, precipitando as proteínas das células superficiais da mucosa e dos tecidos, formando um revestimento protetor e impedindo a ação de enzimas proteolíticas. Também as saponinas, que alteram a permeabilidade das membranas celulares dos microrganismos, causam a destruição, enquanto os óleos essências com atividades terapêuticas variadas abrangem quase todos os sistemas do organismo (Alonso, 2008).

Devido às atividades antifúngicas dos extratos vegetais, essas plantas podem ser opção para o tratamento alternativo ou complementar nas doenças fúngicas, em especial, na candidíase cutânea e de mucosas.

\section{REFERÊNCIA}

ALONSO, J.R. Fitomedicina: curso para profissionais da área da saúde. São Paulo: Pharmabooks, 2008. 195p. CARVALHO, R.J.V. IgA, IgE and IgG subclasses to Candida albicans in serum and vaginal fluid from patients with vulvovaginal candidiasis. Revista Associação Médica Brasileira, v.49, n.4, p.434-8, 2003. FREITAS, F. et al. Rotinas em ginecologia. 4.ed. São Paulo: Artmed Editora, 2003. 624p.

HOLANDA, A.A.R. et al. Candidíase vulvovaginal: sintomatologia, fatores de risco e colonização anal concomitante. Revista Brasileira de Ginecologia e Obstetrícia, v.29, n.1, p.3-9, 2007.

LORENZI, H.; MATOS, F.J.A. Plantas medicinais do Brasil: nativas e exóticas. São Paulo: Instituto Plantarum de Estudos da Flora, 2002. 512p.

PELCZAR JUNIOR, M.J. et al. Microbiologia: conceitos e aplicações. 2.ed. Rio de Janeiro: MAKRON Books do Brasil Editora, 1996. 517p.

PIATO, S. Tratado de ginecologia. São Paulo: Editora Artes Médicas Ltda, 1997. 739p.

SILVA, I.E.F. Obtenção e avaliação da atividade analgésica e anti-inflamatória de extratos hidroalcoólicos da casca, flores e folhas de Tabebuia impetiginosa (Mart. ex DC.) - Ipê Roxo. 2006. 81p. Dissertação (Mestrado em Promoção da Saúde) Universidade de Franca, Franca.

SIMÕES, J.A. The diagnosis of vaginal candidiasis. Revista Brasileira de Ginecologia e Obstetrícia, v.27, n.5, p.233-4, 2005.

TESKE, M.; TRENTINI, A.M.M. Herbarium: compêndio de fitoterapia. 4.ed. Paraná: Herbarium Laboratório Botânico, 2001. 317p. 